\title{
Usefulness of Carbohydrate Antigen 19-9 Test in Healthy People and Necessity of Medical Follow-up in Individuals with Elevated Carbohydrate Antigen 19-9 Level
}

\author{
Sang Pyo Lee', In-Kyung Sung ${ }^{2 *}$, Jeong Hwan Kim², Sun-Young Lee², Hyung Seok Park², Chan Sup Shim² \\ 'Department of Internal Medicine, Hallym University Dongtan Sacred Heart Hospital, Hallym University College of Medicine, Hwaseong, Korea \\ ${ }^{2}$ Department of Internal Medicine, Konkuk University School of Medicine, Seoul, Korea
}

Background: Carbohydrate antigen 19-9 (CA 19-9) is a tumor marker whose level is elevated in many types of cancers and other benign conditions. CA 19-9 levels are frequently found to be elevated in individuals during general health examinations. This study aimed to investigate the clinical characteristics of such individuals and to determine the need for medical follow-up.

Methods: We investigated individuals who underwent a health inspection, including a serum CA 19-9 test, at our center. Their CA 19-9 levels, age, sex, body mass index (BMI), and personal and past histories were investigated. Additionally, subgroup analyses were performed for those who underwent follow-up study for the elevated CA 19-9 levels.

Results: Of 58,498 subjects, 581 (1.0\%) had elevated CA 19-9 levels. Multivariate analyses revealed that older age, female sex, lower BMI, and diabetes were independent predisposing factors for elevated CA 19-9 level. A subgroup analysis revealed that the causative conditions were identified in 129 of 351 subjects (36.8\%). Among them, the causative conditions in 31 subjects ( $8.8 \%$, including four cases of cancer and 15 of benign tumors) were not detected at the initial check-up and were found during the follow-up period.

Conclusion: The use of CA 19-9 as a marker for cancer in healthy individuals is inappropriate. However, medical follow-up in individuals with elevated CA 19-9 levels may be useful because some causative diseases may be detected during follow-up.

Keywords: CA 19-9 Antigen; Diagnostic Reagent Kits; Neoplasms; Tumor Biomarkers

Received: April 19, 2018, Revised: June 27, 2018, Accepted: July 19, 2018

*Corresponding Author: In-Kyung Sung https://orcid.org/0000-0002-3848-5571

Tel: +82-2-2030-5100, Fax: +82-2-2030-7748, E-mail: inksung@kuh.ac.kr 


\section{INTRODUCTION}

Cancer antigen 19-9 (CA 19-9), an intracellular adhesion molecule, is a tumor marker which is used primarily in the management of biliary tract and pancreatic cancers. ${ }^{1-5)}$ Its levels are elevated in most patients with advanced pancreatic cancer and may also be elevated in many kinds of gastrointestinal cancer; e.g., esophageal, stomach, and colorectal cancers as well as hepatocellular carcinoma. ${ }^{6-10)}$ Additionally, CA 19-9 levels may be elevated in individuals with liver cirrhosis, chronic hepatitis, pancreatitis, diseases of the bile ducts, ovarian cystic tumors, chronic renal failure, rheumatic diseases, thyroid diseases, and several benign lung diseases. ${ }^{11-15)}$

According to guidelines from the American Society of Clinical Oncology, screening for CA 19-9 is not useful as a tool for diagnosing cancer. ${ }^{16)}$ The test may wrongly indicate normal levels of CA 19-9 in individuals with pancreato-biliary cancer and can also indicate increased levels in individuals without cancer. ${ }^{17,18)}$

Nevertheless, as the population of individuals that receive regular health examinations increases, we frequently observe elevated CA 19-9 in healthy individuals. In such cases, additional tests are usually performed to determine the cause of the elevation, including imaging, endoscopy, and/or biopsy. However, the next steps remain uncertain in cases in which the cause remains undetermined after these tests.

Previous studies showed that CA 19-9 levels have no value in screening for asymptomatic individuals because the positive value is extremely low. ${ }^{7,819)}$ Furthermore, there has been little long-term followup study on asymptomatic healthy subjects. Only three follow-up studies have been performed, which reported elevated CA 19-9 levels in $0.8 \%-1.7 \%$ of healthy individuals and identified the causative conditions in $25.5 \%-30.3 \%$ of subjects with elevated CA $19-9$ levels. ${ }^{17,18,20)}$ However, short follow-up periods and inadequate investigations of the factors related to elevated CA 19-9 levels may have led to inaccurate results.

This study investigated the clinical characteristics of individuals with elevated CA 19-9 levels identified during general health inspections. Additionally, we tried to determine the need for medical followup in individuals with elevated CA 19-9 levels based on the results of their follow-ups.

\section{METHODS}

\section{Patients}

This retrospective study analyzed the medical records of examinees who underwent health inspection at Konkuk University Medical Center between March 2007 and February 2016. The examinees underwent a serum CA 19-9 test and completed a self-reported questionnaire. The questionnaire contained questions about their cancer history, smoking habits, alcohol consumption, underlying diseases, and medication history. Subjects under 17 years of age and those who did not correctly complete the questionnaires were excluded. Additionally, we investigated the examinees' gender, age, height, and weight by reviewing medical records. The height and weight were measured using a body composition analyzer (X-scan plus II; Jawon Medical Co., Seoul, Korea).

All study procedures were approved by the Institutional Review Board at Konkuk University Hospital (IRB approval no., KUH1010796; Clinical Research Information Service ID, KCT0002107).

\section{Elevated Cancer Antigen 19-9 and Control Groups}

Subjects with elevated CA 19-9 levels were placed into the elevated CA 19-9 group and all others into the control group. The serum level of CA 19-9 was measured using a CA 19-9 kit (Riakey CA 19-9 IRMA tube; Shinjin Medics Inc., Goyang, Korea) in which a value of $>37 \mathrm{U} / \mathrm{mL}$ indicated a significant elevation of CA 19-9. We compared the two

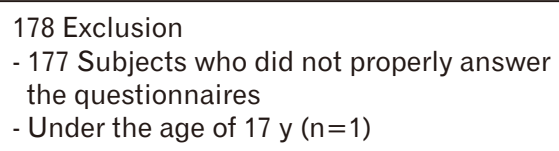

Examinees who received a health inspection including self-reporting

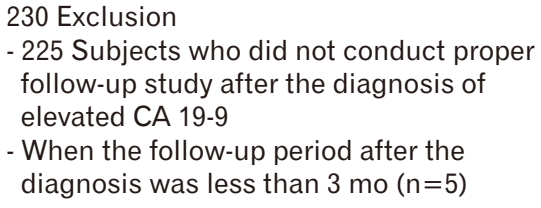

\section{Detection of causative} condition(s): group A

\section{questionnaires and serum CA 19-9 test}

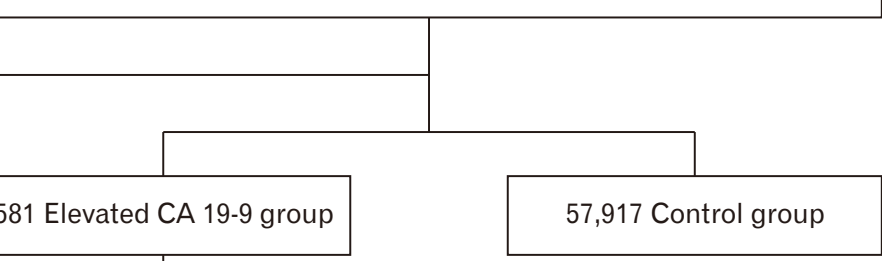

Figure 1. Study flow. A total of 581 and 57,917 subjects were assigned to the elevated CA 19-9 and control groups, respectively. Then, 351 subjects were additionally reviewed for subgroup analysis and the causative condition(s) was detected in 129 subjects (group A) during the follow-up period, while no causative disease was observed in the remaining 222 subjects (group B). CA 19-9, cancer antigen 19-9. 
groups with regard to their sex, age, body mass index (BMI), severity of emotional stress, and personal history.

\section{The Causative Conditions of Elevated Cancer Antigen 19-9 Level}

The medical records of the elevated CA 19-9 group were reviewed to identify the causative condition(s) for the elevation. This study defined the definite causes of CA 19-9 as the following diseases: pancreatic cancer, pancreatic cystic neoplasm, biliary cancer, esophageal cancer, stomach cancer, colon cancer, ovarian cancer, cervical cancer, endometrial cancer, hepatocellular cancer, liver cirrhosis, cholecystitis, cholangitis, and pancreatitis. Other causative diseases included chronic viral hepatitis, inflammatory conditions of the liver and biliary system, biliary stone, choledochal cysts, biliary cystic neoplasm, hyperthyroidism, hypothyroidism, thyroiditis, inflammatory bowel disease, pneumonia, active tuberculosis infection, chronic renal failure, systemic lupus erythematosus, rheumatoid arthritis, interstitial lung disease, and benign ovarian tumor.

\section{Subgroup Analyses of the Patients Who Underwent Follow-up}

A subgroup analysis was performed to determine the need for medical follow-up in individuals with elevated CA 19-9 level. The analysis was based on the medical records from the diagnosis of elevated CA 19-9 level until February 2017. The initial and follow-up studies had to include the following tests at least once during the entire period: abdominal computed tomography (CT) or sonography, chest X-ray, gastroscopy (or upper gastrointestinal series), and colonoscopy (in adults aged $\geq 50$ years). Individuals whose follow-up serum CA 19-9 level tests were not conducted during the follow-up period were excluded from the subgroup analysis. Additionally, patients whose follow-up period of hospital visits was $<3$ months were also excluded. In this study, valid hospital visits were for the following two purposes: (1) visit for routine health inspection and (2) outpatient clinic visit for the treatment of the causative disease or for follow-up observation.

We investigated whether CA 19-9 levels were normalized during the follow-up period and assessed whether diseases developed that might cause an elevated CA 19-9 level. Finally, patients were divided into two groups: those who had a causative disease were categorized into group A and the remaining patients into group B. Additionally, the time of

Table 1. Comparisons between the subjects with elevated and normal CA 19-9 levels

\begin{tabular}{|c|c|c|c|}
\hline Characteristic & Elevated CA 19-9 group $(n=581)$ & Control group $(n=57,917)$ & P-value \\
\hline Age (y) & $47.71 \pm 14.45$ & $44.53 \pm 11.50$ & $<0.001^{\star}$ \\
\hline Range & $17-83$ & $17-96$ & \\
\hline$\geq 50$ & $244(42.0)$ & $17,537(30.3)$ & $<0.001^{\star}$ \\
\hline Female sex & $430(74.0)$ & $26,847(46.4)$ & $<0.001^{*}$ \\
\hline Body mass index $\left(\mathrm{kg} / \mathrm{m}^{2}\right)$ & $22.47 \pm 3.39$ & $23.65 \pm 3.36$ & $<0.001^{*}$ \\
\hline$\geq 25.0$ & $123(21.2)$ & $18,307(31.7)$ & $<0.001^{*}$ \\
\hline$<18.5$ & $48(8.3)$ & $2,471(4.3)$ & $<0.001^{*}$ \\
\hline Past history of cancer & $3(0.5)$ & $527(0.9)$ & 0.319 \\
\hline Family history of cancer & $162(27.9)$ & $16,797(29.0)$ & 0.554 \\
\hline Smoking & & & $<0.001^{*}$ \\
\hline Non-smoker & $358(76.0)$ & $28,005(56.1)$ & \\
\hline Past smoker & $62(13.2)$ & $11,096(22.2)$ & \\
\hline Current smoker & $51(10.8)$ & $10,782(21.6)$ & \\
\hline Alcohol & & & $<0.001^{\star}$ \\
\hline Non-drinker & $171(33.6)$ & $11,474(21.4)$ & \\
\hline Social drinker & $315(61.9)$ & $40,060(74.8)$ & \\
\hline Heavy drinker ${ }^{\dagger}$ & $23(4.5)$ & $2,006(3.7)$ & \\
\hline \multicolumn{4}{|l|}{ Comorbidity } \\
\hline Diabetes & $57(9.8)$ & $2,610(4.5)$ & $<0.001^{*}$ \\
\hline Hypertension & $92(15.8)$ & $7,289(12.6)$ & $0.019^{*}$ \\
\hline Congestive heart disease & $21(3.6)$ & $1,223(2.1)$ & $0.012^{*}$ \\
\hline Stroke & $6(1.0)$ & $383(0.7)$ & 0.273 \\
\hline \multicolumn{4}{|l|}{ Medication } \\
\hline Antiplatelet agent & $45(7.7)$ & $2,294(4.0)$ & $<0.001^{\star}$ \\
\hline Anticoagulant & 0 & $137(0.2)$ & 0.650 \\
\hline Nonsteroidal anti-inflammatory drug & $41(7.1)$ & $2,957(5.1)$ & $0.034^{*}$ \\
\hline
\end{tabular}

Continuous variables were presented as mean \pm standard deviation and analyzed by Mann-Whitney test. All other data were presented as number (\%) and analyzed the chisquare and the Fisher's exact tests. Body mass index, smoking history, alcohol intake, and Brief Encounter Psychosocial Instrument-Korean version level were not measured in $117,8,144,4,449$, and 3,886 subjects, respectively.

CA 19-9, cancer antigen 19-9.

*Significant results. ${ }^{\dagger}$ Heavy drinking was defined as consuming 15 drinks or more per week for men and 8 drinks or more per week for women. 
detection of the causative condition, the frequency of the screening tests, and the levels of other tumor markers were also investigated, including alpha-fetoprotein (AFP), carcinoembryonic antigen (CEA), and cancer antigen 125 (CA 125) by immuno-radiometric assay (Riakey IRMA tube, Shinjin Medics Inc.). CA 125 level was only measured in women. Levels of AFP $>10 \mathrm{ng} / \mathrm{mL}$, CEA $>5 \mathrm{ng} / \mathrm{mL}$ in non-smokers (>7.5 in smokers), and CA $125>35 \mathrm{U} / \mathrm{mL}$ indicated significant elevations.

\section{Statistical Analysis}

The categorical variables were summarized as numbers (\%) and analyzed by $\chi^{2}$ or Fisher's exact tests, while continuous variables were shown as mean \pm standard deviation and analyzed by Student $t$ - or Mann-Whitney tests. Logistic regression analyses were then performed to estimate the odds ratios (ORs) and 95\% confidence intervals (CIs) for factors that were independently associated with the elevation of CA 19-9 level. All analyses were conducted using IBM SPSS Statistics for Windows ver. 19.0 (IBM Corp., Armonk, NY, USA) and $\mathrm{P}<0.05$ was considered statistically significant.

\section{RESULTS}

\section{Comparisons between the Elevated Cancer Antigen 19-9 and Control Groups}

Among the 58,676 subjects visiting our health care center, 178 were excluded from the study for inappropriate or poor answers on the questionnaires or for young age (Figure 1). Overall, 581 subjects (1.0\%) were assigned to the elevated CA 19-9 group and 57,917 to the control group. Four hundred and thirty subjects $(74.0 \%)$ in the elevated CA 19-9 group and 26,847 subjects $(46.4 \%)$ in the control group were female (Table 1). The mean age of the elevated CA 19-9 group was $47.71 \pm 14.45$ years (range, 17-83 years) and the mean BMI was $22.47 \pm 3.39 \mathrm{~kg} / \mathrm{m}^{2}$ (range, $13.83-54.44 \mathrm{~kg} / \mathrm{m}^{2}$ ). The mean age of those in the control group was $44.53 \pm 11.50$ years (range, $17-96$ years) and the mean BMI was $23.65 \pm 3.36 \mathrm{~kg} / \mathrm{m}^{2}$ (range, $14.43-47.81 \mathrm{~kg} / \mathrm{m}^{2}$ ).

\section{Predisposing Factors for Elevated Cancer Antigen 19-9 Levels}

Subjects with elevated CA 19-9 levels were generally older $(\mathrm{P}<0.001)$; predominantly female $(\mathrm{P}<0.001)$; had a lower $\mathrm{BMI}(\mathrm{P}<0.001)$; were non-smokers $(\mathrm{P}<0.001)$ and non-drinkers $(\mathrm{P}<0.001)$; showed a higher incidence of diabetes $(\mathrm{P}<0.001)$, hypertension $(\mathrm{P}=0.019)$, and congestive heart disease $(\mathrm{P}=0.012)$; and were more likely to be on antiplatelet agents $(\mathrm{P}<0.001)$ and nonsteroidal anti-inflammatory drugs medication $(\mathrm{P}=0.034)$ than the control group (Table 1$)$. There was no statistically significant difference in the history of cancer between the elevated CA 19-9 and control groups. Multivariate analyses revealed that older age (OR, 1.021; 95\% CI, 1.013-1.030; $\mathrm{P}<0.001$ ), female sex (OR, 2.903; 95\% CI, 2.283-3.692; $\mathrm{P}<0.001$ ), lower BMI (OR, 0.897; 95\% CI, 0.867-0.928; $\mathrm{P}<0.001$ ), and diabetes (OR, 2.021; 95\% CI, 1.412-2.891; $\mathrm{P}<0.001)$ were independent predisposing factors for elevated CA 19-9 levels (Table 2).

\section{Causative Conditions in the Elevated Cancer Antigen 19-9 Group}

Among the subjects in the elevated CA 19-9 group, causative conditions were found in 185 (31.8\%) during the follow-up period. Twentyfive cancers related to elevated CA 19-9 levels were detected (pancreatic cancer, 6; cholangiocarcinoma, 1; colon cancer, 4; lung cancer, 2; ovarian cancer, 2; gastric cancer, 7 ; cervical cancer, 2 ; and endometrial cancer, 1). No hepatocellular carcinomas or esophageal cancers were found. The detailed causative conditions of elevated CA 19-9 levels are shown in Table 3.

\section{Subgroup Analyses}

Of the 581 subjects with elevated CA 19-9 levels, 230 were excluded from subgroup analysis for the reasons described in the methods section. Of 351 subjects analyzed, the mean number of CA 19-9 tests was $3.99 \pm 2.29$ and the total follow-up period of hospital visits was $42 \pm 23.9$ months. The causative condition(s) were detected in 129 subjects (36.8\%, group A) during the entire follow-up period, while no caus-

Table 2. Predictors of elevated cancer antigen 19-9 levels

\begin{tabular}{|c|c|c|c|c|}
\hline \multirow{2}{*}{ Variable } & \multicolumn{2}{|c|}{ Univariate analysis } & \multicolumn{2}{|c|}{ Multivariate analysis } \\
\hline & $\mathrm{OR}(95 \% \mathrm{Cl})$ & P-value & Adjusted OR (95\% Cl) & P-value \\
\hline Age & $1.022(1.016-1.029)$ & $<0.001$ & $1.021(1.013-1.030)$ & $<0.001^{*}$ \\
\hline Female sex & $3.296(2.736-3.970)$ & $<0.001$ & $2.903(2.283-3.692)$ & $<0.001^{*}$ \\
\hline Body mass index & $0.890(0.866-0.914)$ & $<0.001$ & $0.897(0.867-0.928)$ & $<0.001^{*}$ \\
\hline Current smoker & $0.440(0.329-0.589)$ & $<0.001$ & $0.945(0.684-1.306)$ & 0.732 \\
\hline Heavy drinker & $1.216(0.798-1.851)$ & 0.363 & - & \\
\hline Diabetes & $2.305(1.749-3.038)$ & $<0.001$ & $2.021(1.412-2.891)$ & $<0.001^{*}$ \\
\hline Hypertension & $1.307(1.044-1.635)$ & 0.019 & $1.083(0.795-1.476)$ & 0.612 \\
\hline Congestive heart disease & 1.738 (1.120-2.697) & 0.014 & $1.245(0.730-2.122)$ & 0.422 \\
\hline Antiplatelet agent & $2.036(1.497-2.767)$ & $<0.001$ & $1.365(0.911-2.045)$ & 0.132 \\
\hline Nonsteroidal anti-inflammatory drug & $1.411(1.025-1.943)$ & 0.035 & $1.025(0.704-1.491)$ & 0.898 \\
\hline
\end{tabular}

Univariate and multivariate logistic regression analyses were performed.

$\mathrm{OR}$, odds ratio; $\mathrm{Cl}$, confidence interval.

*Significant results. 
Table 3. Causative conditions of elevated CA 19-9 levels in the elevated CA 19-9 group $(\mathrm{n}=581)$

\begin{tabular}{|c|c|}
\hline Variable & No. of subjects $(\%)$ \\
\hline Total number of the subjects with causative disease(s) & 185 \\
\hline Subjects with two or more causative diseases & 39 \\
\hline \multicolumn{2}{|l|}{ Causative diseases of elevated CA 19-9 level } \\
\hline \multicolumn{2}{|l|}{ Definite causes } \\
\hline Pancreatic cancer & 6 \\
\hline Pancreatic cystic neoplasm & 10 \\
\hline Cholangiocarcinoma & 1 \\
\hline Colon cancer & 4 \\
\hline Lung cancer (non-small cell lung cancer) & 2 \\
\hline Ovarian cancer & 2 \\
\hline Liver cirrhosis & 24 \\
\hline Cholecystitis or cholangitis & 10 \\
\hline Acute or chronic pancreatitis & 5 \\
\hline \multicolumn{2}{|l|}{ Possible causes } \\
\hline Chronic viral hepatitis & 26 \\
\hline Biliary stone & 37 \\
\hline Biliary cystadenoma & 1 \\
\hline Choledochal cysts & 1 \\
\hline Clonorchiasis with peribiliary fibrosis & 1 \\
\hline Hyperthyroidism, hypothyroidism, and (or) thyroiditis & 19 \\
\hline Inflammatory bowel disease & 2 \\
\hline Active tuberculosis & 4 \\
\hline Pneumonia (except tuberculosis) & 3 \\
\hline Interstitial lung disease & 3 \\
\hline Systemic lupus erythematosus & 1 \\
\hline Chronic renal failure & 2 \\
\hline Gastric cancer & 7 \\
\hline Cervical cancer & 2 \\
\hline Endometrial cancer & 1 \\
\hline Benign ovarian tumor & 56 \\
\hline \multicolumn{2}{|l|}{ Other conditions } \\
\hline Papillary thyroid cancer & 4 \\
\hline Breast cancer & 3 \\
\hline Prostatic cancer & 1 \\
\hline Endometriosis, endometritis, cervicitis & 4 \\
\hline Polycystic kidney disease & 6 \\
\hline Cholecystectomy state & 12 \\
\hline Gallbladder polyp & 45 \\
\hline Uterine myoma & 61 \\
\hline Colonic adenoma & 69 \\
\hline
\end{tabular}

Chronic viral hepatitis included 22 subjects with hepatitis $B$ and four with hepatitis $C$. Biliary stone included 35 cases of gall bladder stone and one each with common bile duct stone and intrahepatic duct stone, respectively. Thyroid disease included two cases with hyperthyroidism, 13 with hypothyroidism, and four with thyroiditis. Inflammatory bowel disease included one case of ulcerative colitis and one with Crohn's disease. Active tuberculosis included three cases of pulmonary tuberculosis and one case of tuberculosis colitis. Histological classifications of benign ovarian tumors confirmed by operation were as follows: endometriosis of ovary, 10; mature cystic teratoma, 4; follicular cyst, 1; cystic mesothelioma, 1; sero-mucinous borderline tumor, 1; and dermoid cyst, 1 .

CA 19-9, cancer antigen 19-9.

ative disease was found in the remaining 222 subjects (63.2\%, group B) (Table 4).

The individuals in group A were older than those in group $\mathrm{B}$ $(\mathrm{P}=0.010)$. The initial and maximal CA 19-9 levels were significantly higher in group $\mathrm{A}$ than those in group $\mathrm{B}(\mathrm{P}=0.045$ and 0.030$)$. Elevated
CEA and CA 125 levels were more common in group A than in group B $(\mathrm{P}=0.010$ and 0.009$)$. There were no statistically significant differences in sex, BMI, or diabetes between the two groups.

Eight patients (6.2\%) from group A died from the causative disease (gastric cancer, 4; colon cancer, 2; pancreatic cancer, 1; and endometrial cancer, 1) and no patients in group B died during the follow-up period. In group A, the CA 19-9 levels of 38 subjects (29.5\%) were normalized after surgery or medication. Meanwhile, elevated CA 19-9 levels were maintained in 28 subjects (12.6\%) from group B without a causative condition.

The levels of some tumor markers also rose along with those of CA 19-9. CEA increased in three (50\%) out of six cases of gastric cancer, in all four (100\%) colon cancers, and in one (2.3\%) of 43 benign ovarian tumors. CA 125 level increased in one (50\%) of two ovarian cancers, in the (100\%) case of endometrial cancer, in two $(66.7 \%)$ of three colon cancers in women, and in 15 (34.9\%) of 43 benign ovarian tumors. The AFP level increased in one (2.3\%) of 43 cases with benign ovarian tumors.

\section{Causative Conditions Found during Follow-up in Group A} The causative conditions of 31 subjects ( $8.8 \%$ of the subgroup, 32 cases) with elevated CA 19-9 levels were not detected on initial check-up and were identified during the follow-up period (Table 5). The mean duration from initial check-up to detection was $29 \pm 18.3$ months. The causative conditions included 19 benign or malignant tumors (in 18 subjects) (Supplementary Table 1); cancer was found in four subjects (cholangiocarcinoma, gastric cancer, ovarian cancer, and cervical cancer) and benign tumors in 14 subjects (three pancreatic cystic neoplasms, one biliary cystadenoma, and 11 benign ovarian tumors).

\section{DISCUSSION}

Our results showed that serum CA 19-9 levels are elevated in about $1 \%$ of health examinees and that elevated levels are more common in elderly individuals, women, diabetics, and individuals with low BMI. The causative conditions were confirmed as benign tumors and cancer in 67 and 25 cases, respectively. In other words, cancers related to increased CA $19-9$ level were found in only $0.04 \%$ of all cases. Additionally, in many cases, CA 19-9 findings did not play a major role in detecting cancer. Therefore, if the objective of the CA 19-9 test is to detect early cancer, the test is costly and inefficient, as previous studies showed. ${ }^{1,9,16)}$ Thus, CA 19-9 is not suitable as a diagnostic marker for cancer in healthy individuals.

In previous studies, the percentages of subjects with elevated CA $19-9$ levels ranged from $0.8 \%$ to $1.7 \%{ }^{17,18,20)}$ The reason for the relatively low prevalence rate in our study was that the proportions of women and elderly people in the population were lower than those in other studies. In addition, our study identified diabetes mellitus as an independent predisposing factor for elevated CA 19-9 level. This result indirectly supports previous findings that diabetes might be increasingly associated with pancreatic mass such as pancreatic cancer and pan- 
Table 4. Comparisons of subjects who were followed up ( $n=351$, subgroup analysis)

\begin{tabular}{|c|c|c|c|}
\hline Variable & $\begin{array}{l}\text { Group } A \text { ( } n=129 \text { ): detection of } \\
\text { causative condition(s) }\end{array}$ & $\begin{array}{l}\text { Group } B(n=222) \text { : no detection of causative } \\
\text { condition(s) during the entire period }\end{array}$ & P-value \\
\hline Total follow-up period of hospital visit (mo) & $42.19 \pm 24.29$ & $42.18 \pm 23.67$ & 0.997 \\
\hline Total follow-up period of CA 19-9 test (mo) & $38.79 \pm 23.91$ & $39.59 \pm 23.78$ & 0.761 \\
\hline Age $(y)$ & $50.12 \pm 14.54$ & $46.02 \pm 14.13$ & $0.010^{*}$ \\
\hline Female sex & 99 (76.7) & $166(74.8)$ & 0.702 \\
\hline Body mass index $\left(\mathrm{kg} / \mathrm{m}^{2}\right)$ & $22.58 \pm 3.30$ & $22.09 \pm 2.97$ & 0.143 \\
\hline Diabetes & 14 (10.9) & $14(6.3)$ & 0.153 \\
\hline Death during the follow-up period & $8(6.2)$ & 0 & $<0.001^{*}$ \\
\hline Frequency of CA 19-9 test & $4.10(2.48)$ & $3.92(2.18)$ & 0.485 \\
\hline \multicolumn{4}{|l|}{ CA 19-9 levels during follow-up (U/mL) } \\
\hline Initial & $199.61 \pm 774.68$ & $61.24 \pm 71.42$ & $0.045^{\star}$ \\
\hline Maximum & $397.04 \pm 1,671.82$ & $74.02 \pm 108.62$ & $0.030^{*}$ \\
\hline Minimum & $105.04 \pm 727.42$ & $21.99 \pm 17.34$ & 0.197 \\
\hline Change in CA 19-9 level during follow-up & & & 0.077 \\
\hline Normalization & $87(67.4)$ & $170(76.6)$ & \\
\hline Normalization after medication ${ }^{\dagger}$ & 5 & 0 & \\
\hline Normalization after surgery ${ }^{\ddagger}$ & 33 & 0 & \\
\hline Sustained high levels & $28(21.7)$ & $28(12.6)$ & \\
\hline Fluctuating levels & $14(10.9)$ & $24(10.4)$ & \\
\hline \multicolumn{4}{|c|}{ Frequency of health screening tests during the follow-up period } \\
\hline Upper gastrointestinal series & $0.24 \pm 0.72$ & $0.23 \pm 0.64$ & 0.886 \\
\hline Gastroscopy & $2.52 \pm 1.24$ & $2.54 \pm 1.32$ & 0.882 \\
\hline Colonoscopy & $1.21 \pm 0.86$ & $1.08 \pm 0.88$ & 0.171 \\
\hline Abdominal computed tomography & $1.42 \pm 1.40$ & $0.59 \pm 0.78$ & $<0.001^{*}$ \\
\hline Abdominal ultrasonography & $2.97 \pm 1.48$ & $2.96 \pm 1.49$ & 0.976 \\
\hline Pelvic sonography in women & $1.46 \pm 1.05$ & $1.19 \pm 0.64$ & 0.076 \\
\hline \multicolumn{4}{|l|}{ Elevation of other tumor marker levels } \\
\hline AFP $(n g / m L)$ & $2.90 \pm 3.11$ & $2.62 \pm 1.65$ & 0.351 \\
\hline AFP $>10 \mathrm{ng} / \mathrm{mL}$ & $3(2.3)$ & $2(0.9)$ & 0.361 \\
\hline CEA (ng/mL) & $25.42 \pm 163.50$ & $1.50 \pm 1.08$ & 0.099 \\
\hline CEA $>5 \mathrm{ng} / \mathrm{mL}$ in non-smoker, $>7.5 \mathrm{ng} / \mathrm{mL}$ in smoker & $10(7.8)$ & $4(1.8)$ & $0.010^{\star}$ \\
\hline CA 125 in women (U/mL) & $32.83 \pm 35.56$ & $19.76 \pm 18.00$ & $0.003^{*}$ \\
\hline $\mathrm{CA} 125>35 \mathrm{U} / \mathrm{mL}$ & $24(24.2)$ & $19(11.5)$ & $0.009^{*}$ \\
\hline
\end{tabular}

Continuous variables were presented as mean \pm standard deviation and analyzed by Student $\mathrm{t}$-tests and Mann-Whitney tests. All other data were presented as numbers (\%) and analyzed by chi-square and Fisher's exact tests. Body mass index and CEA were not measured in one and three subjects, respectively. CA 125 was only measured in women and was not measured in one female subject.

CA 19-9, cancer antigen 19-9; AFP, alpha-fetoprotein; CEA, carcinoembryonic antigen; CA 125, cancer antigen 125.

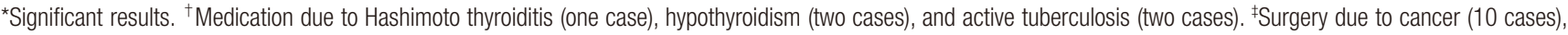
benign ovarian tumor (19 cases), biliary cystadenoma (one case), cholecystitis (two cases), and interstitial lung disease (one case).

creatic neuroendocrine tumors. ${ }^{5,21-23)}$ In subgroup analysis, the causative conditions were detected in 129 subjects (36.8\%) and the causative conditions of 31 subjects were not detected on initial check-up but were identified during the follow-up period. Cancer and benign tumors were found during follow-up in four and 14 subjects, respectively. Therefore, a large number of tumors may be found during follow-up study. Additionally, eight patients (6.2\%) from group A died during the follow-up period due to the causative cancers in all cases. Therefore, follow-up testing for individuals with elevated CA 19-9 levels may be helpful.

Our review of the cases of causative tumors detected during the follow-up period highlights the need for follow-up tests. In the case of the subject with cholangiocarcinoma (Supplementary Table 1, case 1), the initial CT scan result was normal. However, 14 months later, cholangiocarcinoma with liver metastasis was found in the follow-up CT scan. In the case of other cancers (cases 2, 3, and 4), the cancers were detected in their early stages by continuous monitoring and were completely cured after surgery. Additionally, in many benign tumor cases (cases 8, 9, 11, 13, and 14), CA 19-9 levels were normalized after surgical resection of the tumors.

Elevated CEA and CA 125 levels were more common in group A than in group $B$ because there were many gastrointestinal cancer and ovarian tumor cases in group A. However, in 28 cases of benign ovarian tumor (65.1\%) and one case of ovarian cancer (50\%), CA 19-9 levels increased without elevation of CA 125 levels. Therefore, evaluation of gynecologic disorders may be needed for women with elevated CA 19-9 and normal CA 125 levels.

Our study has some limitations. Firstly, the sample size was not large enough for conclusions regarding the optimal screening interval and indispensable inspection items based on our results. In our study, the 


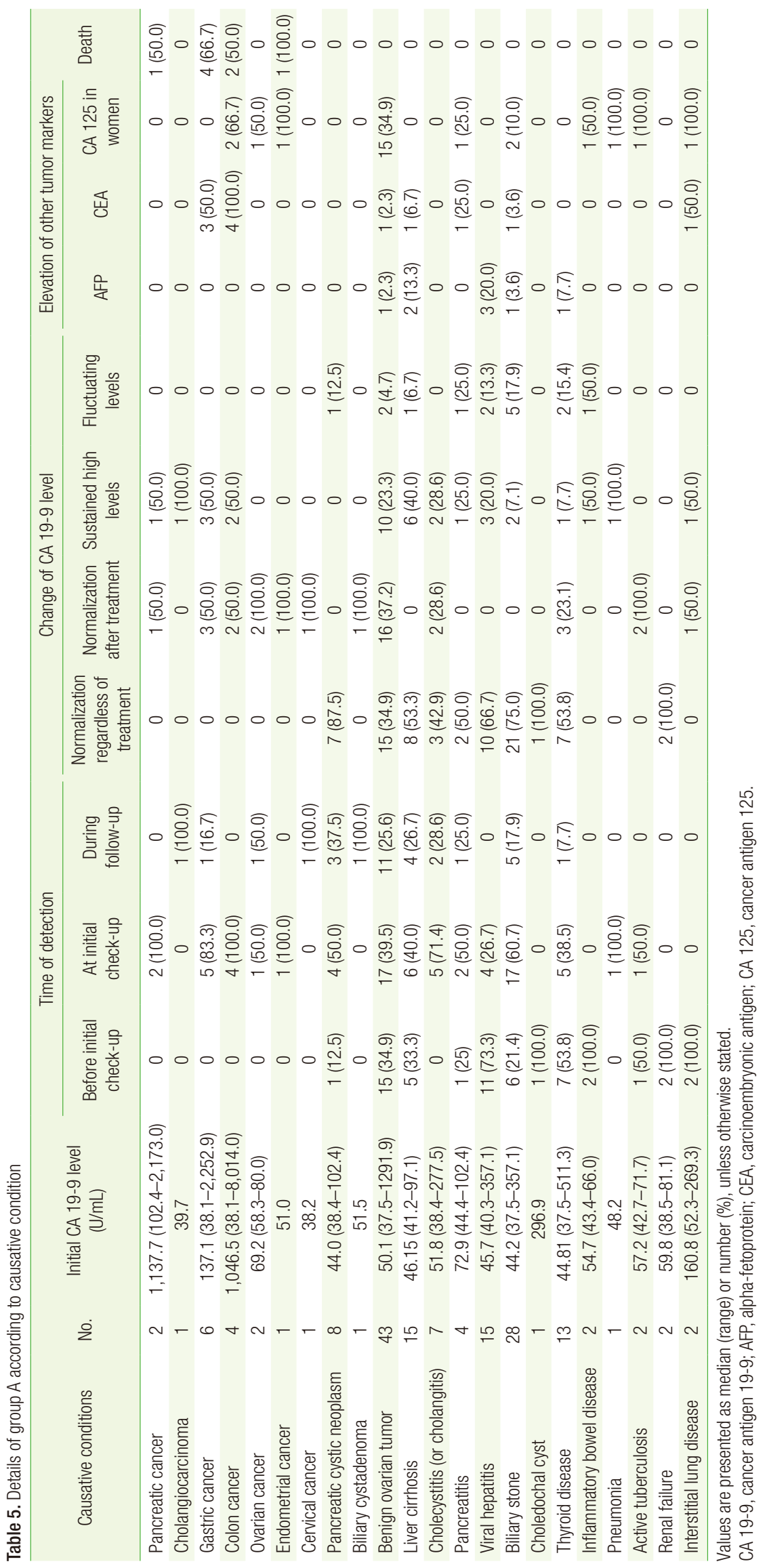


detection time for the causative conditions and changing patterns of CA 19-9 levels varied from case to case. Additional large-scale and long-term follow-up studies are required. Secondly, abdominal CT scans were more commonly performed in group A than in group B in our study. This is because the subjects in group A more often had a follow-up CT scan after detection of the causative diseases. Lastly, there were some missing values for BMI, smoking history, alcohol intake, Brief Encounter Psychosocial Instrument-Korean version, CEA, and CA 125 levels. However, there were no additional missing values in the other data.

In conclusion, serum CA 19-9 levels were elevated in about $1 \%$ of health examinees, more commonly in elderly individuals, women, diabetics, and individuals with low BMI. The causative conditions were detected in $36.8 \%$ of subjects with elevated CA 19-9 levels; in $8.8 \%$ of the subjects, the causative conditions were not detected on initial check-up but were found during the follow-up period. Therefore, the use of CA 19-9 as a screening test for cancer in healthy individuals is inappropriate. However, follow-up tests for individuals with elevated CA 19-9 levels may be needed because some clinically significant causative diseases may be found during follow-up.

\section{CONFLICT OF INTEREST}

No potential conflict of interest relevant to this article was reported.

\section{SUPPLEMENTARY MATERIALS}

Supplementary materials can be found via https://doi.org/10.4082/ kjfm.18.0057. Supplementary Table 1. Causative tumors found during the follow-up period.

\section{ORCID}

Sang Pyo Lee: https://orcid.org/0000-0002-4495-3714

In-Kyung Sung: https://orcid.org/0000-0002-3848-5571

Jeong Hwan Kim: https://orcid.org/0000-0001-5432-8229

Sun-Young Lee: https://orcid.org/0000-0003-4146-6686

Hyung Seok Park: https://orcid.org/0000-0001-7362-4306

Chan Sup Shim: https://orcid.org/0000-0002-2475-6887

\section{REFERENCES}

1. Perkins GL, Slater ED, Sanders GK, Prichard JG. Serum tumor markers. Am Fam Physician 2003;68:1075-82.

2. Magnani JL. The discovery, biology, and drug development of sialyl Lea and sialyl Lex. Arch Biochem Biophys 2004;426:122-31.

3. Satake K, Takeuchi T, Homma T, Ozaki H. CA19-9 as a screening and diagnostic tool in symptomatic patients: the Japanese experience. Pancreas 1994;9:703-6.

4. Daamen LA, Groot VP, Heerkens HD, Intven MPW, van Santvoort HC, Molenaar IQ. Systematic review on the role of serum tumor markers in the detection of recurrent pancreatic cancer. HPB (Oxford) 2018;20:
297-304.

5. Choe JW, Kim HJ, Kim JS, Cha J, Joo MK, Lee BJ, et al. Usefulness of CA 19-9 for pancreatic cancer screening in patients with new-onset diabetes. Hepatobiliary Pancreat Dis Int 2018;17:263-8.

6. Zhang Y, Yang J, Li H, Wu Y, Zhang H, Chen W. Tumor markers CA199, CA242 and CEA in the diagnosis of pancreatic cancer: a meta-analysis. Int J Clin Exp Med 2015;8:11683-91.

7. Kim HJ, Kim MH, Myung SJ, Lim BC, Park ET, Yoo KS, et al. A new strategy for the application of CA19-9 in the differentiation of pancreaticobiliary cancer: analysis using a receiver operating characteristic curve. Am J Gastroenterol 1999;94:1941-6.

8. Frebourg T, Bercoff E, Manchon N, Senant J, Basuyau JP, Breton P, et al. The evaluation of CA 19-9 antigen level in the early detection of pancreatic cancer: a prospective study of 866 patients. Cancer 1988;62: 2287-90.

9. Goonetilleke KS, Siriwardena AK. Systematic review of carbohydrate antigen (CA 19-9) as a biochemical marker in the diagnosis of pancreatic cancer. Eur J Surg Oncol 2007;33:266-70.

10. Kim NH, Lee MY, Park JH, Park DI, Sohn CI, Choi K, et al. Serum CEA and CA 19-9 levels are associated with the presence and severity of colorectal neoplasia. Yonsei Med J 2017;58:918-24.

11. Kim HR, Lee CH, Kim YW, Han SK, Shim YS, Yim JJ. Increased CA 19-9 level in patients without malignant disease. Clin Chem Lab Med 2009;47:750-4.

12. Shimomura C, Eguchi K, Kawakami A, Migita K, Nakao H, Otsubo T, et al. Elevation of a tumor associated antigen CA 19-9 levels in patients with rheumatic diseases. J Rheumatol 1989;16:1410-5.

13. Xiaofang Y, Yue Z, Xialian X, Zhibin Y. Serum tumour markers in patients with chronic kidney disease. Scand J Clin Lab Invest 2007;67: 661-7.

14. Sagi-Dain L, Lavie O, Auslander R, Sagi S. CA 19-9 in evaluation of adnexal mass: retrospective cohort analysis and review of the literature. Int J Biol Markers 2015;30:e333-40.

15. Kim JY, Kim SH, Kim SY. Elevated serum CA 19-9 at screening tests: underlying conditions and role of abdominopelvic CT. Eur Radiol 2014;24:2435-48.

16. Locker GY, Hamilton S, Harris J, Jessup JM, Kemeny N, Macdonald JS, et al. ASCO 2006 update of recommendations for the use of tumor markers in gastrointestinal cancer. J Clin Oncol 2006;24:5313-27.

17. Kim JE, Lee KT, Lee JK, Paik SW, Rhee JC, Choi KW. Clinical usefulness of carbohydrate antigen 19-9 as a screening test for pancreatic cancer in an asymptomatic population. J Gastroenterol Hepatol 2004;19:1826.

18. Kim BJ, Lee KT, Moon TG, Kang P, Lee JK, Kim JJ, et al. How do we interpret an elevated carbohydrate antigen 19-9 level in asymptomatic subjects? Dig Liver Dis 2009;41:364-9.

19. Wang HY, Hsieh CH, Wen CN, Wen YH, Chen CH, Lu JJ. Cancers screening in an asymptomatic population by using multiple tumour markers. PLoS One 2016;11:e0158285.

20. Tong Y, Song Z, Zhu W. Study of an elevated carbohydrate antigen 19-9 concentration in a large health check-up cohort in China. Clin Chem Lab Med 2013;51:1459-66.

21. Ben Q, Cai Q, Li Z, Yuan Y, Ning X, Deng S, et al. The relationship between new-onset diabetes mellitus and pancreatic cancer risk: a casecontrol study. Eur J Cancer 2011;47:248-54. 
22. Uygur-Bayramicli O, Dabak R, Orbay E, Dolapcioglu C, Sargin M, Kilicoglu G, et al. Type 2 diabetes mellitus and CA 19-9 levels. World J Gastroenterol 2007;13:5357-9.

23. Haugvik SP, Hedenstrom P, Korsaeth E, Valente R, Hayes A, Siuka D, et al. Diabetes, smoking, alcohol use, and family history of cancer as risk factors for pancreatic neuroendocrine tumors: a systematic review and meta-analysis. Neuroendocrinology 2015;101:133-42. 